\title{
The role of alanine in the acute response of Giardia intestinalis to hypo-osmotic shock
}

\author{
Jeong H. Park, Philip J. Schofield and Michael R. Edwards
}

Author for correspondence: Michael R. Edwards. Fax: +6123136271. e-mail: M.Edwards@unsw.edu.au

School of Biochemistry and Molecular Genetics, University of New South Wales, Sydney, NSW 2052, Australia

\begin{abstract}
The effect of medium hypo-osmolality on cell volume and intracellular amino acid composition was studied in the protozoan parasite Giardia intestinalis. When $G$. intestinalis was exposed to hypotonic medium, it initially swelled by $40 \%$ of its original volume and then decreased its volume, thus demonstrating a regulatory volume decrease process (RVD). These processes were accompanied by a rapid release of intracellular neutral amino acids, especially alanine, but not by amino acids with net charges such as glutamate and ornithine. The net alanine efflux was $\mathrm{Na}^{+}$and $\mathrm{Cl}^{-}$independent, and sensitive to medium osmolality. Alanine efflux was sigmoidal with respect to medium osmolality, with an approximately linear relationship over a range of 250 mOsm $\mathbf{~ k g}^{-1}$. Alanine efflux was also sensitive to temperature, and an Arrhenius plot gave a $Q_{10}$ of 3.6 and an activation energy of $25 \mathrm{kcal} \mathrm{mol}^{-1}$ $\left(105 \mathrm{~kJ} \mathrm{~mol}^{-1}\right.$ ), suggesting that a carrier-type transport protein, or uniport, was involved in the net alanine efflux under hypotonic conditions. This volumeactivated (VA) alanine efflux was not inhibited by ionophores or chloride channel blockers. Of the potential inhibitors tested, only phydroxymercuribenzoate inhibited net alanine efflux. This thiol reagent also inhibited giardial RVD, suggesting that alanine efflux plays a significant role in this process. The VA (alanine) uniport was able to transport 2-aminoisobutyric acid (AIB), a structural analogue of alanine which is frequently used for the characterization of eukaryotic alanine transport, but which is not transported by Giardia under isotonic conditions. On the basis of AIB uptake under hypotonic conditions and lack of transactivation of AIB efflux from AlB-loaded cells by external $10 \mathrm{mM}$ alanine or glycine under isotonic conditions, it is evident that the VA (alanine) uniport is different from the previously reported (alanine) antiport.
\end{abstract}

Keywords: Giardia intestinalis, hypotonicity, alanine efflux, regulatory volume decrease

\section{INTRODUCTION}

The protozoan parasite Giardia intestinalis contains very active pathways for amino acid metabolism (Edwards $e t$ al., 1989; Schofield et al., 1992). Alanine, in particular, is of crucial importance, since it is produced as a major endproduct of giardial metabolism, with concentrations of up to $30 \mathrm{mM}$ accumulating in the growth medium (Edwards et al., 1989). Such high concentrations have triggered interest in alanine transport by Giardia and it has recently

Abbreviations: AlB, 2-aminoisobutyric acid; PHMB, p-hydroxymercuribenzoic acid; RVD, regulatory volume decrease; VA, volumeactivated. been demonstrated that giardial alanine transport is mediated by an antiporter which has a broad substrate specificity, since external amino acids which are structurally similar to alanine inhibit its influx and activate its efflux (Edwards et al., 1993; Nygaard et al., 1994). This antiporter differs significantly from other eukaryotic amino acid transporters with respect to the lack of its ability to transport 2-aminoisobutyric acid (AIB). However, the alanine antiport mechanism is not sufficient to account for the release of alanine during giardial growth, since the disappearance of external amino acids from the growth medium does not balance the alanine efflux (Nygaard et al., 1994). This suggests the involvement of other alanine transporter(s) which function in alanine efflux. 
On exposure of a cell which lacks a rigid cell wall to hypoosmolality, its volume will increase, resulting in cell rupture due mainly to osmotically induced water influx, unless the cell has an effective osmoregulatory mechanism. In many tissues and organisms such osmolysis can be avoided by the activation of membrane transporter(s) that reduce the concentrations of intracellular small molecules or ions, with the result that the cell undergoes a regulatory volume decrease (RVD) (Chamberlin \& Strange, 1989). There are many examples of amino acids acting as osmoregulators, although there is species specificity as to which amino acids are released in response to hypoosmotic stress. The high intracellular alanine concentration in $G$. intestinalis indicates that alanine may function as a major osmoregulator in this parasite (Knodler et al., 1994) and a volume-activated alanine transporter could also account for the observed net alanine efflux during growth. The mechanism(s) of osmoregulation in Giardia are of interest in relation to the development of such processes during eukaryotic evolution, since recent evidence places this protozoon on one of the earliest branches of the eukaryotic evolutionary tree (Lenaers et al., 1988; Sogin et al., 1989).

In this study we evaluated the temporal changes in cell size of $G$. intestinalis in response to hypo-osmotic stress. We found that massive decreases in intracellular amino acids pools occur in parallel with decreasing medium osmolalities and we also demonstrated the dependence of unidirectional alanine efflux on temperature and medium osmolality. We have shown the existence of a giardial uniporter for alanine which differs from the giardial antiporter. It also differs from amino acid uniporters previously reported from other sources in respect to its susceptibility to inhibitors and the independence from $\mathrm{Na}^{+}$for activation.

\section{METHODS}

Parasite growth and cell preparation. Giardia intestinalis (Portland 1 strain) was grown anaerobically as described previously (Edwards et al., 1989) in TYI-S-33 medium containing $30 \mathrm{mM}$ glucose and augmented by $5 \mathrm{mM}$ arginine. For some growth experiments, medium was diluted with sterile distilled water and maintained at $37^{\circ} \mathrm{C}$. At defined times, cells were detached by leaving on ice for $30 \mathrm{~min}$, and enumerated using a haemocytometer. After centrifugation at $700 \mathrm{~g}$ for $15 \mathrm{~min}$, growth medium was removed to measure its osmolality. Fresh cultures were initiated after $72 \mathrm{~h}$ in all experiments. For experiments involving whole cells, harvested trophozoites were prepared as described previously (Nygaard et al., 1994). The resulting cell pellets were resuspended in cold phosphatebuffered saline (PBS) $\left[1.8 \mathrm{mM} \quad \mathrm{KH}_{2} \mathrm{PO}_{4} / 5 \mathrm{mM}\right.$ $\mathrm{K}_{2} \mathrm{HPO}_{4} / 0.9 \%$ (w/v) $\left.\mathrm{NaCl}, \mathrm{pH} 7.4\right]$ and kept on ice for transport studies. The osmolality of the spent medium and PBS buffer was $308 \mathrm{mOsm} \mathrm{kg}$. PBS buffer was used as a standard isotonic incubation medium, unless otherwise stated, and change in the osmotic pressure of the incubation medium was achieved by appropriate combinations of PBS and distilled water.

Alanine efflux. Approximately $2 \times 10^{8}$ cold PBS-washed-cells were incubated for $10 \mathrm{~min}$ at $37^{\circ} \mathrm{C}$ in $3 \mathrm{ml}$ PBS containing $1 \mathrm{mM} \mathrm{L}-\left[2,3-{ }^{3} \mathrm{H}\right]$ alanine $\left(2.5 \mu \mathrm{Ci} \mathrm{m}^{-1} ; 92.5 \mathrm{kBq} \mathrm{ml}^{-1}\right)$ and $1 \mathrm{mM}$
L-cycloserine to pre-load them with radiolabelled alanine. The loaded cells were rapidly washed free of extracellular radioactivity (four washes with ice-cold PBS) and then resuspended in $2 \mathrm{ml}$ ice-cold PBS. Alanine efflux at $37^{\circ} \mathrm{C}$ was initiated by mixing $0.1 \mathrm{ml}$ of a suspension of loaded cells with $0.4 \mathrm{ml}$ prewarmed incubation medium of various osmolalities representing finally up to $50 \%$ dilutions of the isotonic PBS buffer. At predetermined intervals, duplicate $0.2 \mathrm{ml}$ aliquots were removed, transferred into Beckman microfuge tubes and centrifuged through oil as described previously (Edwards $\mathrm{et}$ al., 1993). A sample $(0.15 \mathrm{ml})$ of the supernatant was removed, transferred to scintillant containing $0.85 \mathrm{ml}$ water and the radioactivity determined. The remaining aqueous layer was aspirated and the surface of the oil gently washed free of external radioactivity (three washes with distilled water). After carefully aspirating the oil and remaining water, the pellets were processed for intracellular radioactivity as described previously (Edwards et al., 1993).

Alanine efflux of loaded cells was also measured in the presence of potential inhibitors. $\left[{ }^{3} \mathrm{H}\right]$ Alanine-loaded cells $(0.05 \mathrm{ml})$ were incubated with inhibitors in isotonic medium for $5 \mathrm{~min}$ at $37^{\circ} \mathrm{C}$ and transferred to the pre-warmed mixture of distilled water and PBS buffer containing the same concentration of the above inhibitors and $1 \mathrm{mM}$ L-cycloserine to give a final medium osmolality of $248 \mathrm{mOsm} \mathrm{kg} \mathrm{m}^{-1}$. After incubation for $5 \mathrm{~min}$ at $37^{\circ} \mathrm{C}, 0.2 \mathrm{ml}$ of the cell suspension was taken, processed and the radioactivity determined as described above. $\left[{ }^{3} \mathrm{H}\right]$ Alanineloaded cells in isotonic medium without any inhibitor were used as a control. $p$-Hydroxymercuribenzoate (PHMB) was initially dissolved by the dropwise addition of $1 \mathrm{M} \mathrm{NaOH}$ solution and made up to volume with PBS. Valinomycin, nigericin, gramicidin and nonactin were dissolved in $95 \%$ (v/v) ethanol $\left(20 \mu \mathrm{g} \mathrm{ml}^{-1}\right)$ and diluted with PBS to the desired concentration.

To determine the effect of $\mathrm{Na}^{+}$and $\mathrm{Cl}^{-}$on alanine efflux, $\mathrm{NaCl}$ was replaced by choline chloride, $\mathrm{KCl}$, mannitol or sodium lactate in PBS buffer. A concentration of $150 \mathrm{mM}$ was used for choline chloride, $\mathrm{KCl}$ and sodium lactate, and $300 \mathrm{mM}$ for mannitol to give osmolalities equal to that of isotonic PBS buffer. $\left[{ }^{3} \mathrm{H}\right]$ Alanine-loaded cells $(0 \cdot 05 \mathrm{ml})$ were added to a mixture of $0.2 \mathrm{ml}$ PBS buffer and $0.25 \mathrm{ml}$ solutions containing substitutes of $\mathrm{NaCl}$. Incubation was carried out for $5 \mathrm{~min}$ at $37^{\circ} \mathrm{C}$ and subsequent cell washing, processing and radioactivity determinations were as described previously.

Influx and efflux of 2-aminoisobutyric acid (AIB). To investigate AIB influx under hypotonic conditions, PBSresuspended cells $(0.05 \mathrm{ml})$ were added to $0.2 \mathrm{ml}$ of a mixture of PBS buffer and distilled water containing $20 \mathrm{mM}\left[1{ }^{14} \mathrm{C}\right] \mathrm{AIB}$ $\left(2 \mu \mathrm{Ci} \mathrm{ml} l^{-1} ; 74 \mathrm{kBq} \mathrm{ml}^{-1}\right)$ to give a medium osmolality of $157 \mathrm{mOsm} \mathrm{kg}{ }^{-1}$. Incubation was carried out at $37^{\circ} \mathrm{C}$. After defined time intervals, $0.2 \mathrm{ml}$ cell suspension was removed, centrifuged through oil, processed and the radioactivity determined as indicated above. PBS-resuspended cells in isotonic incubation medium were used as a control.

To determine the efflux of AIB, cells were pre-loaded with AIB under hypotonic conditions (157 mOsm kg ${ }^{-1}$ ). PBSresuspended cells $(0.76 \mathrm{ml})$ were added to distilled water $(1.24 \mathrm{ml})$ containing $40 \mathrm{mM} \quad\left[1-^{14} \mathrm{C}\right] \mathrm{AIB} \quad(4 \mu \mathrm{Ci} \mathrm{ml})^{-1}$; $148 \mathrm{kBq} \mathrm{ml}^{-1}$ ), and incubated for $15 \mathrm{~min}$ at $37^{\circ} \mathrm{C}$. Cells were then sedimented, resuspended in isotonic PBS buffer and washed free of extracellular radioactivity (five washes with ice-cold PBS). AIB efflux was initiated by mixing $0.125 \mathrm{ml}$ suspension of $\left[{ }^{14} \mathrm{C}\right]$ AIB-loaded cells with $0 \cdot 125 \mathrm{ml}$ pre-warmed distilled water or isotonic incubation medium. To investigate the effect of exogenous amino acids on the efflux of AIB the loaded cells were also mixed with isotonic medium containing either $10 \mathrm{mM}$ 
L-alanine or $10 \mathrm{mM}$ glycine. After incubation for $10 \mathrm{~min}$ at $37^{\circ} \mathrm{C}, 0.2 \mathrm{ml}$ cell suspension was then taken, centrifuged through oil, processed and the radioactivity in cells was determined as indicated above.

Amino acid analysis. PBS-resuspended cells $(0.2 \mathrm{ml})$ were added to $0.8 \mathrm{ml}$ pre-warmed diluted PBS buffer to give final osmolalities of 248 and $157 \mathrm{mOsm} \mathrm{kg}^{-1}$. After incubation for $5 \mathrm{~min}$ at $37^{\circ} \mathrm{C}$, duplicate $0.4 \mathrm{ml}$ aliquots of the cell suspension were taken, and centrifuged directly through oil into $0.1 \mathrm{ml}$ $20 \%(\mathrm{w} / \mathrm{v})$ sulphosalicylic acid and $0.02 \mathrm{ml} 5 \mathrm{mM} \beta$-alanine. The mixture containing the cell pellet was assayed for the intracellular amino acids (Nygaard et al., 1994). For the extracellular amino acid analysis, $0.35 \mathrm{ml}$ of the supernatant of each cell suspension was added to $0.2 \mathrm{ml} 20 \%$ (w/v) sulphosalicylic acid and $4 \mu \mathrm{l} 5 \mathrm{mM} \beta$-alanine. The mixture was centrifuged for $5 \mathrm{~min}$ in a Beckman microfuge, and the supernatant retained. The supernatant was then evaporated to dryness and resuspended in $0.2 \mathrm{ml} \mathrm{Li}-\mathrm{A}$ Beckman diluent. After filtration through a $0.2 \mu \mathrm{m}$ membrane filter, the sample was analysed on a Beckman 6300 amino acid analyser.

Other methods. Osmolality was measured using a ONE-TEN Osmometer (FISKE). The protein content of PBS-resuspended Giardia was determined by the Lowry method using bovine serum albumin as a standard. For the measurement of radioactivity, samples were dissolved in $10 \mathrm{ml} 0.5 \%(\mathrm{w} / \mathrm{v}) 2,5-$ diphenyloxazole in Triton X-100/toluene $(1: 2, \mathrm{v} / \mathrm{v})$, and then radioactivity was measured using a Packard Tri-Carb 1900 Liquid Scintillation System. To determine intracellular water space $0.1 \mathrm{ml}$ of cells were pre-warmed in isotonic PBS for $5 \mathrm{~min}$ at $25^{\circ} \mathrm{C}$ prior to the addition of $0.1 \mathrm{ml}$ distilled water. Incubations were carried out at $25^{\circ} \mathrm{C}$ for various intervals and intracellular water space was determined using the method of Padan et al. (1976).

\section{RESULTS}

\section{Giardial growth at lower osmolalities}

Trophozoites were inoculated into growth media of different osmolalities, achieved by simply diluting the medium with sterile distilled water. The osmolality of the standard growth medium was $272 \mathrm{mOsm} \mathrm{kg}^{-1}$. G. intestinalis grew well in a hypotonic growth medium of $192 \mathrm{mOsm} \mathrm{kg}^{-1}$, although to a lesser extent than that in standard growth medium. The osmolality of both growth media was increased by $14 \%$ of the initial medium osmolality over the test periods, reaching final values of 308 and $218 \mathrm{mOsm} \mathrm{kg}^{-1}$. Since $G$. intestinalis was normally harvested at the medium osmolality of $308 \mathrm{mOsm} \mathrm{kg}^{-1}$, $308 \mathrm{mOsm} \mathrm{kg} \mathrm{kg}^{-1}$ was defined as isosmolality for the purpose of this paper. The trophozoites were also inoculated in $50 \%$ dilutions of original growth medium $\left(157 \mathrm{mOsm} \mathrm{kg}{ }^{-1}\right)$. These cells grew at the same rate as those in the above osmolalities for $1 \mathrm{~d}$ but then further growth stopped. The decreased final cell mass and short growth period probably resulted from the decreased availability of nutrients, rather than the decreased osmolality itself, since the rates of growth were initially equal at all osmolalities. Intracellular amino acid analysis established that the pool concentration of alanine in trophozoites grown for $2 \mathrm{~d}$ in $70 \%$ diluted medium was only $60 \%$ of that in control cells grown in normal undiluted medium (data not shown).

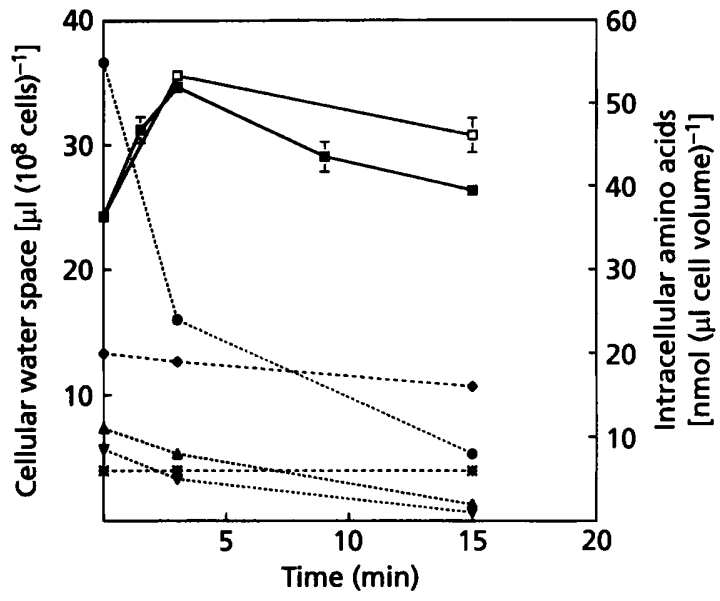

Fig. 1. Cell volume changes in response to hypo-osmotic stress. Cells were grown at an initial osmolality of $272 \mathrm{mOsm} \mathrm{kg}^{-1}$, and cell volumes (intracellular water space) were then determined at $25^{\circ} \mathrm{C}$ in PBS buffer diluted with water giving a final osmolality of 157 mOsm $\mathrm{kg}^{-1}$, using $\left[{ }^{14} \mathrm{C}\right.$ ]inulin carboxylic acid and ${ }^{3} \mathrm{H}_{2} \mathrm{O}$ in the absence $(\square)$ or presence $(\square)$ of $0.1 \mathrm{mM}$ PHMB. Cell volume values are means \pm SD $(n=4)$. Intracellular amino acid pools of the 0,3 and $15 \mathrm{~min}$ samples were determined: alanine; $\boldsymbol{\nabla}$, valine; $\boldsymbol{\Delta}$, glycine; $\diamond$, glutamate; $*$, ornithine (values are the means of duplicates).

\section{Cell volume change in response to hypo-osmotic stress}

It is well known that cells generally swell initially in response to hypo-osmotic stress and then return to their original volume as compensatory mechanisms are activated (regulatory volume decrease, RVD) (Chamberlin \& Strange, 1989). $\left[{ }^{14} \mathrm{C}\right]$ Inulin carboxylic acid and ${ }^{3} \mathrm{H}_{2} \mathrm{O}$ were used as markers for extracellular and pellet water space respectively. Intracellular water space was calculated by subtracting extracellular water space from the pellet water space. Fig. 1 shows the volume change of $G$. intestinalis in response to medium osmotic pressure of $157 \mathrm{mOsm} \mathrm{kg}^{-1}$ as a function of time. When the cells were exposed to hypo-osmotic stress, cell volume rapidly increased by $40 \%$ of its original value within the first 3 min. Giardia then underwent an RVD which required more time than the cell swelling process. Cell volume had not fully recovered its original value after $15 \mathrm{~min}$ and remained approximately $5 \%$ higher than its original value, even after the volume regulation process was apparently complete.

Subsequent intracellular amino acid analysis of the cell samples collected at $3 \mathrm{~min}$ and $15 \mathrm{~min}$ showed that all intracellular amino acids were not equally decreased (Fig. 1). There were marked decreases in the intracellular concentrations of some neutral amino acids, namely alanine, glycine and valine, during the swelling and the RVD process, whereas no significant decreases in the intracellular levels of glutamate and ornithine were observed. The values shown for the concentration of intracellular amino acids are based on the calculation that $1 \mathrm{mg}$ cell protein represents $4 \mu \mathrm{l}$ intracellular water space. 

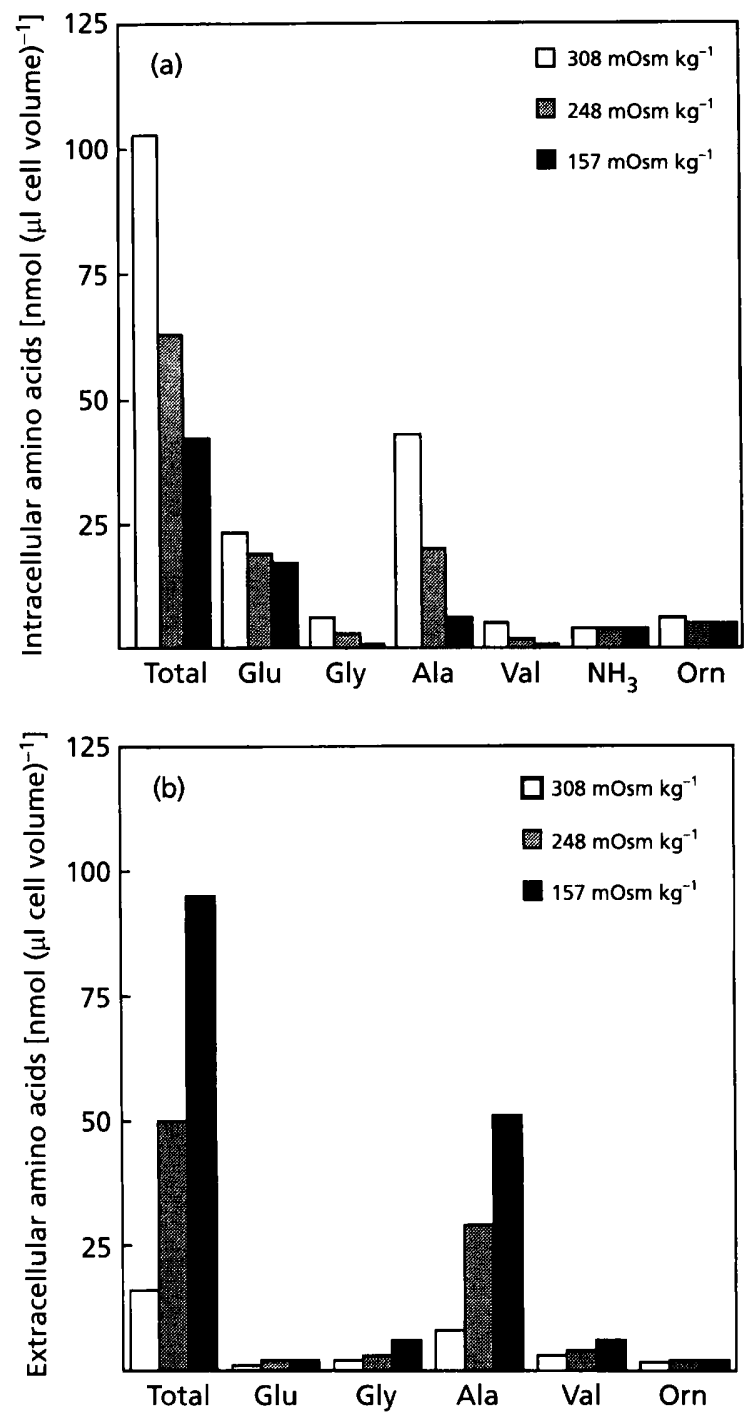

Fig. 2. Effect of medium osmolality on (a) intracellular and (b) extracellular amino acids. The cells were incubated at $37^{\circ} \mathrm{C}$ for $5 \mathrm{~min}$ in media of various osmolalities produced by diluting isotonic PBS buffer with water. The values are the means of duplicates.

\section{Effect of medium osmolality on amino acid pool}

Analyses of intracellular and extracellular amino acid were performed when cells were transferred to hypotonic media of $248 \mathrm{mOsm} \mathrm{kg}^{-1}$ and $157 \mathrm{mOsm} \mathrm{kg}^{-1}$, by diluting isotonic medium with distilled water. The exposure of the cells to the two hypotonic conditions released approximately $40 \%$ and $60 \%$ respectively of total free amino acids from the cells in parallel with the change in medium osmolalities. Fig. 2(a) shows the changes in the concentrations of the total free amino acid pool and five individual amino acids which in total contributed $85 \%$ of the amino acid pool under isotonic conditions. Intracellular alanine accounted for $40 \%$ of the total free amino acids pool under isotonic conditions and was considerably decreased in response to decreasing medium osmolalities. Alanine was no longer the major amino acid at an

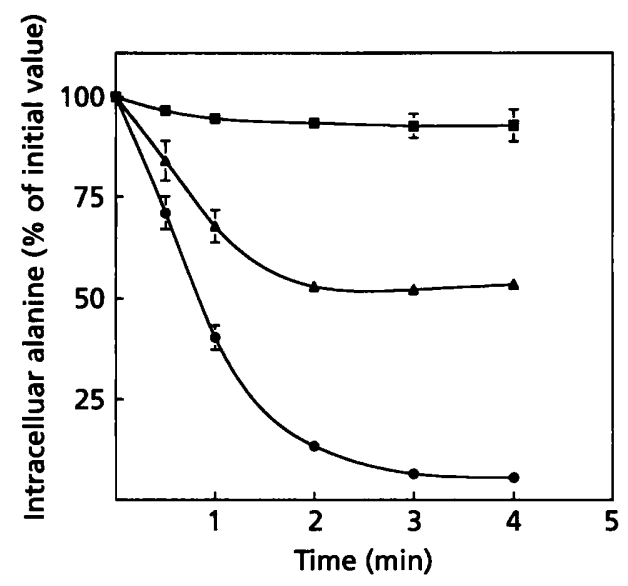

Fig. 3. Time course of alanine efflux from G. intestinalis trophozoites under hypotonic conditions. Intracellular $\left[{ }^{3} \mathrm{H}\right]$ alanine was measured at $37^{\circ} \mathrm{C}$ in media of $308(\square), 248(\Delta)$ and $157(0) \mathrm{mOsm} \mathrm{kg}^{-1}$. Values are expressed as a percentage of the initial radiolabel, which corresponded to an intracellular concentration of $45 \mathrm{nmol}\left(\mu\right.$ l cell volume) ${ }^{-1}$, and are means \pm SD $(n=3)$.

osmolality of $157 \mathrm{mOsm} \mathrm{kg}^{-1}$ and accounted for only $9 \%$ of the total amino acid pool. Among intracellular amino acids, other neutral amino acids showed the same pattern of decrease as alanine in response to hypo-osmotic stress. However, the glutamate pool decreased only slightly and consequently glutamate was the major amino acid at the medium osmotic pressure of $157 \mathrm{mOsm} \mathrm{kg}^{-1}$, accounting for $40 \%$ of the total amino acid pool. Intracellular ornithine and ammonia also remained unchanged. To corroborate these results, the simultaneous changes in extracellular amino acids were measured (Fig. 2b). The increases in extracellular amino acids with decreasing medium osmolalities corresponded to the decrease in their intracellular counterparts.

Since alanine was the major intracellular amino acid and it was released rapidly in response to hypo-osmotic shock, subsequent experiments in the present study were designed for analysis of alanine efflux under isotonic and hypotonic conditions using $\left[{ }^{3} \mathrm{H}\right]$ alanine as a marker.

\section{Effect of medium osmolality on alanine efflux}

$\left[{ }^{3} \mathrm{H}\right]$ Alanine-loaded cells were used to observe the effect of medium osmolality on rates of alanine efflux. PBS buffer was diluted with distilled water to obtain various osmolalities. Experiments were performed in the presence of $1 \mathrm{mM}$ L-cycloserine to inhibit alanine catabolism as described previously (Edwards et al., 1993).

Fig. 3 shows the efflux of intracellular alanine as a function of time. The rate of efflux observed in isotonic medium at $37^{\circ} \mathrm{C}$ was negligible over the test period, compared to that observed under hypotonic conditions. Dilution of the isotonic medium by $20 \%$ and by $50 \%$ with distilled water resulted in a dramatic increase in alanine release. Most of the alanine effluxed at each osmolality was 


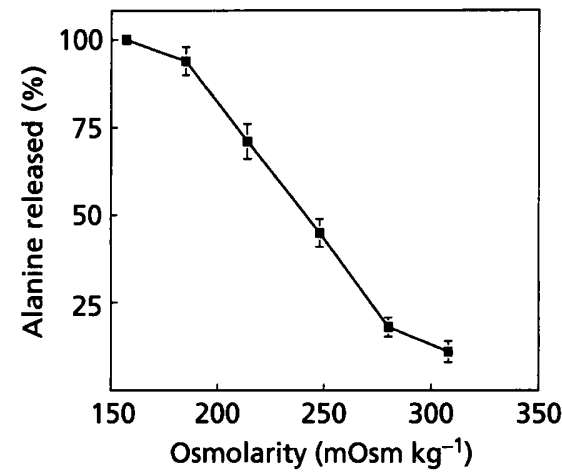

Fig. 4. Effect of medium osmolality on alanine efflux. The amount of intracellular $\left[{ }^{3} \mathrm{H}\right]$ alanine was measured in the media after $5 \mathrm{~min}$ incubation at $37^{\circ} \mathrm{C}$. Values are expressed as percentages of the radiolabel effluxed in $5 \mathrm{~min}$ at $157 \mathrm{mOsm}$ $\mathrm{kg}^{-1}$ and are means $\pm \mathrm{SD}(n=3)$.

released within 2 min of the hypotonic challenge. Exogenous $1 \mathrm{mM}$-alanine in isotonic medium resulted in the efflux of approximately $50 \%$ of the intracellular label in $5 \mathrm{~min}$, in agreement with the previous description of the giardial alanine antiport (Edwards et al., 1993; Nygaard et al., 1994).

Alanine efflux was observed over a 5 min time period in incubation media of various osmolalities (Fig. 4). Alanine efflux increased dramatically as medium osmolality was decreased. The response curve appeared to be sigmoidal, with an approximately linear increase in the amount of alanine released over $5 \mathrm{~min}$ as a function of decreased osmolality between 280 and $180 \mathrm{mOsm} \mathrm{kg}^{-1}$. A similar sigmoidal shape for the osmolality response curve was previously reported in the promastigotes of protozoan parasite Leishmania major, where alanine was the primary osmolyte in response to hypo-osmotic stress (Darling et al., 1990).

Temperature dependency plots of transport rates are a common way to predict the type of transport process. Preloaded cells were incubated in PBS diluted to $248 \mathrm{mOsm}$ $\mathrm{kg}^{-1}$ for 2 min at various temperatures. The Arrhenius plot of alanine efflux over the temperature range $4-37^{\circ} \mathrm{C}$ is shown in Fig. 5. No breakpoint was observed over this temperature range; the $Q_{10}$ value of alanine efflux was $3 \cdot 6$, with an activation energy of $25 \mathrm{kcal} \mathrm{mol}^{-1}(105 \mathrm{~kJ}$ $\left.\mathrm{mol}^{-1}\right)$.

\section{AIB transport under hypotonic conditions}

Recently, Edwards et al. (1993) and Nygaard et al. (1994) reported that Giardia contained an antiport for alanine influx and efflux, and this antiport showed a broad specificity for other amino acids structurally similar to Lalanine. A characteristic feature of this antiport was its inability to utilize AIB, a compound that is commonly used as a non-metabolizable analogue of alanine in investigation of alanine transport in other systems (Lepley \& Mukkada, 1983; Shotwell \& Oxender, 1983). On this

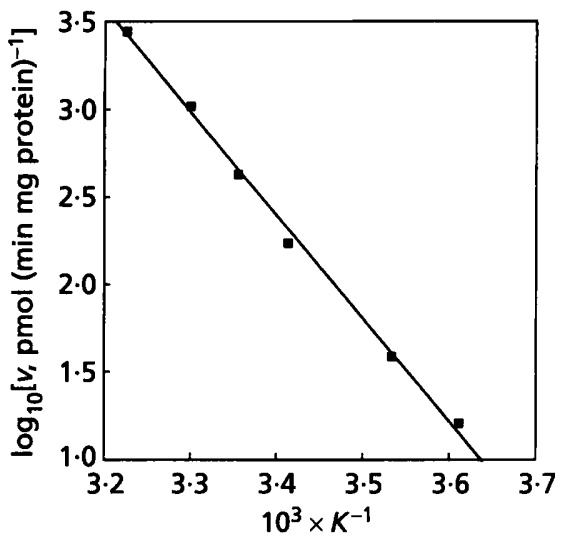

Fig. 5. Arrhenius plot of alanine efflux at a medium osmolality of $248 \mathrm{mOsm} \mathrm{kg}{ }^{-1}$. The initial rate of efflux of $\left[{ }^{3} \mathrm{H}\right.$ ]alanine was determined using 2 min time points in the temperature range $4-37^{\circ} \mathrm{C}$. Values are representative of three separate experiments.

basis, AIB was chosen to investigate the membrane transporter responsible for the acute response of Giardia to hypo-osmotic stress. When the cells were exposed to hypo-osmotic pressure of $157 \mathrm{mOsm} \mathrm{kg}^{-1}$ in the presence of $20 \mathrm{mM}$ external $\left[{ }^{14} \mathrm{C}\right] \mathrm{AIB}$, the intracellular concentration of AIB increased substantially to $13 \mathrm{mM}$ within $3 \mathrm{~min}$, and reached a level of $16 \mathrm{mM}$ within $15 \mathrm{~min}$, representing an intracellular concentration of AIB approximately $80 \%$ of that in external medium. Clearly AIB was taken up by Giardia under hypotonic conditions, in contrast to the absence of AIB uptake under isotonic conditions. When the concentration of external AIB was augmented to $40 \mathrm{mM}$ under identical conditions, the increase in intracellular AIB concentration after $15 \mathrm{~min}$ corresponded to the concentration of external AIB. However, as predicted, no significant change in intracellular AIB was again observed when the cells were incubated in isotonic medium (data not shown).

To investigate AIB efflux under hypotonic conditions, cells were exposed to hypotonic medium of $157 \mathrm{mOsm}$ $\mathrm{kg}^{-1}$ containing $40 \mathrm{mM}\left[{ }^{14} \mathrm{C}\right] \mathrm{AIB}$ for $15 \mathrm{~min}$, transferred to isotonic medium so that $\left[{ }^{14} \mathrm{C}\right] \mathrm{AIB}$ was trapped inside the cells, and washed. When the AIB-loaded cells were subjected to a medium osmolality of $157 \mathrm{mOsm} \mathrm{kg}{ }^{-1}$, approximately $60 \%$ of the intracellular AIB pool was released over a $10 \mathrm{~min}$ period (Fig. 6). However, under isotonic conditions there was very little efflux of AIB. Exogenous $10 \mathrm{mM}$ alanine or glycine in isotonic incubation medium did not cause efflux of the intracellular AIB, although intracellular amino acid analysis showed the expected increase in intracellular alanine and glycine pools during the $10 \mathrm{~min}$ incubation period.

\section{Effect of $\mathrm{Na}^{+}, \mathrm{Cl}^{-}$and inhibitors on alanine efflux}

The activation of alanine efflux under hypotonic conditions may have resulted from the reduction of the concentration of $\mathrm{Na}^{+}$and $\mathrm{Cl}^{-}$ions resulting from diluting 


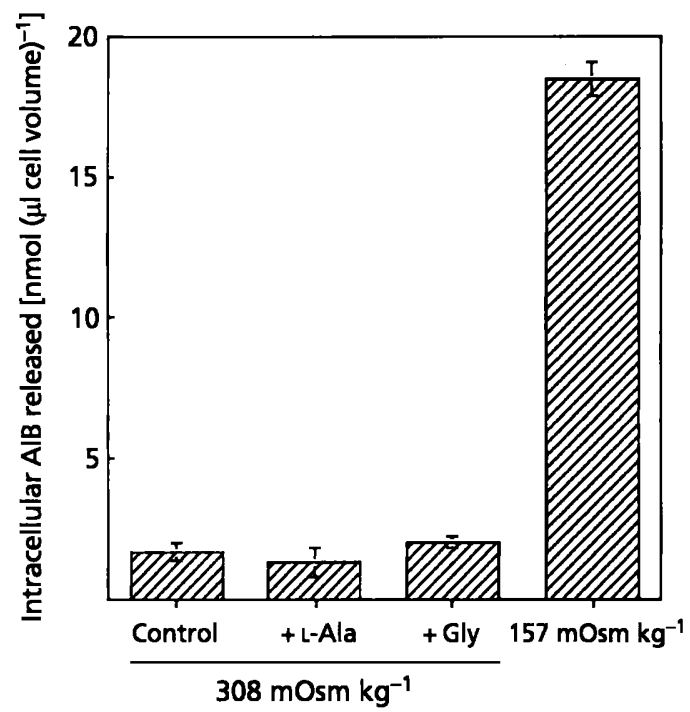

Fig. 6. AlB efflux under different conditions. $\left[{ }^{14} \mathrm{C}\right] \mathrm{AlB}$-loaded cells were prepared under hypotonic conditions. The amount of AIB released was measured after incubation of loaded cells for $10 \mathrm{~min}$ at $37^{\circ} \mathrm{C}$ under hypotonic conditions (157 mOsm $\mathrm{kg}^{-1}$ ). AlB efflux was also measured under isotonic conditions with and without exogenous $10 \mathrm{mM}$ alanine or glycine. Each value is the mean \pm SD $(n=3)$.

PBS with distilled water. However, replacing the $\mathrm{NaCl}$ of PBS with choline chloride, $\mathrm{KCl}$, mannitol or sodium lactate had no effect on the efflux of intracellular alanine under isotonic or hypotonic conditions (data not shown).

A number of potential inhibitors, including thiol reagents, chloride channel blockers and ionophores, were screened for their ability to inhibit alanine efflux under hypotonic conditions of $248 \mathrm{mOsm} \mathrm{kg}{ }^{-1}$. $\left[{ }^{3} \mathrm{H}\right]$ Alanine-loaded cells were preincubated with inhibitors in isotonic medium for 5 min at $37^{\circ} \mathrm{C}$, before exposure to hypo-osmotic stress. Of the inhibitors tested, only $0.1 \mathrm{mM}$ PHMB showed significant inhibition ( $45 \%$ ) of alanine efflux under hypotonic conditions. Iodoacetate $(0.1 \mathrm{mM})$, furosemide $(0.1 \mathrm{mM})$, niflumate $(0.1 \mathrm{mM})$, valinomycin $\left(0.2 \mu \mathrm{g} \mathrm{m}^{-1}\right)$, nigericin $\left(0 \cdot 2 \mu \mathrm{g} \mathrm{ml}^{-1}\right)$, gramicidin $\left(0 \cdot 2 \mu \mathrm{g} \mathrm{ml}^{-1}\right)$, nonactin $\left(0 \cdot 2 \mu \mathrm{g} \mathrm{ml}^{-1}\right)$ and phlorizin $(0.1 \mathrm{mM})$ showed no inhibitory effect (data not shown).

The temporal change in intracellular water space was measured in the presence of $0.1 \mathrm{mM}$ PHMB at hypoosmotic pressure of $157 \mathrm{mOsm} \mathrm{kg}^{-1}$ to assess whether the inhibition of alanine efflux affected the RVD response (Fig. 1). When G. intestinalis was exposed to hypo-osmotic stress, the rapid cell volume increase was similar in the presence and absence of PHMB. However, in the presence of $0.1 \mathrm{mM}$ PHMB the RVD was inhibited, and the giardial trophozoites remained swollen. At the $15 \mathrm{~min}$ time point after the hypo-osmotic stress, the cell volume in the presence of PHMB was significantly higher than in uninhibited controls as assessed by the unpaired twotailed $t$-test $(P<0.05)$.

\section{DISCUSSION}

G. intestinalis is a protozoan parasite that lives in the human intestine. Since intestinal fluid varies in tonicity, as a result of the feeding pattern of the host, the ability to adapt to changes in osmolality could be important for trophozoite survival. The observations that $G$. intestinalis is able to survive and grow well at reduced osmolalities compared to normal culture medium suggest that it contains systems which sense and respond to hypoosmotic stress.

In common with many animal cells (Chamberlin \& Strange, 1989), G. intestinalis changed its cell volume in response to the hypo-osmotic stress. Reducing the medium osmolality by $50 \%$ resulted in the cells swelling to approximately 1.4 times their original size within $3 \mathrm{~min}$ (Fig. 1). The cells then underwent a RVD, returning to close to the original volume over the next $10 \mathrm{~min}$. This pattern of swelling and recovery is similar in magnitude, but different in time course, to that observed in promastigotes of another protozoan, Leishmania major (Darling et al., 1990). In Giardia the cell swelling process and RVD were also accompanied by rapid release of intracellular free amino acids, especially alanine (Fig. 1). This loss of intracellular amino acids appeared to decrease the intracellular osmolality and thus reduce the osmotically driven influx of water which might otherwise lead to cell lysis and allow for subsequent volume recovery. However, not all intracellular free amino acids were released at the same rate. The intracellular concentrations of neutral amino acids, namely alanine, glycine and valine, decreased rapidly, but not those of glutamate or ornithine. The rate of release of neutral amino acids and the total amount released after the completion of volume recovery were related to the decrease in medium osmolality (Figs 2-4). These observations suggest that the release of neutral amino acids is responsible for the giardial RVD and, in particular, alanine is the primary osmolyte since it is present in highest intracellular concentration under isotonic conditions and is rapidly lost under hypo-osmotic conditions. Efflux of intracellular amino acid in response to cell swelling has been observed in many organisms and tissues (Chamberlin, 1989). The identity of the amino acid which functions as the primary intracellular osmolyte is species-specific, reflecting the divergence of amino acids as osmolytes. The use of alanine as an osmolyte by Giardia is of particular interest as recent evidence places this organism on one of the earliest if not the earliest branch point in the evolution of eukaryotes (Lenaers et al., 1988; Sogin et al., 1989). It may be significant that Leishmania major, which is also placed on the earliest branch of the eukaryotic evolutionary tree (Briones et al., 1992), also utilizes alanine as an osmolyte (Darling et al., 1990). In addition to net efflux of amino acids in response to hypo-osmotic stress, there are several reports of increased oxidation of amino acids and increased ammonia production (Gilles, 1987; Moyes $\mathrm{et} \mathrm{al.,}$ 1986). However, this possibility can be excluded in the giardial response to hypo-osmotic shock, since the decrease in the concentration of intracellular amino acids corresponded to an increase in its external concentrations 
(Fig. 2a, b) and there was no increase in ammonia, one of the products of amino acid oxidation.

Recent reports indicate that alanine influx and efflux by $G$. intestinalis under isotonic conditions are largely mediated by an antiport, since exogenous alanine and its analogues such as glycine, serine and threonine simultaneously inhibit alanine influx and stimulate alanine efflux (Edwards et al., 1993; Nygaard et al., 1994). However, in contrast to this bidirectional antiport system observed under isotonic conditions, unidirectional alanine efflux occurred when Giardia was exposed to hypo-osmotic stress (Fig. 3). This observation suggests that alanine efflux under hypo-osmotic stress is via an (alanine) uniport that is functionally different from the previously described (alanine) antiport. This unidirectional alanine efflux was also highly temperature sensitive (Fig. 5). The $Q_{10}$ of 3.6 and activation energy of $25 \mathrm{kcal} \mathrm{mol}^{-1}$ were indicative of protein-mediated transport, rather than simple diffusion or opening of prelytic pores. The alanine uniporter appeared to sense the differences in medium osmolality (Fig. 4), since it controlled the release of intracellular alanine in parallel with external osmolalities, suggesting that the alanine uniport is osmosensitive or volumeactivated (VA).

AIB, a non-metabolizable analogue of alanine, is frequently used to investigate alanine transport mechanism in eukaryotes (Lepley \& Mukkada, 1983; Shotwell \& Oxender, 1983). When Giardia cells were exposed to hypo-osmotic stress in the presence of external AIB, influx was observed. This was surprising, since no significant AIB influx was observed in Giardia under isotonic conditions. It proved possible to pre-load trophozoites with $\left[{ }^{14} \mathrm{C}\right] \mathrm{AIB}$ under hypotonic conditions. This label was retained under isotonic conditions (Fig. 6) and efflux was not stimulated by external $10 \mathrm{mM}$ alanine and glycine. This lack of transactivation by external amino acids is in agreement with previous reports that AIB is not transported via the alanine antiport (Edwards et al., 1993; Nygaard et al., 1994). However, efflux was observed when the cells were returned to hypotonic medium (Fig. 6). These observations imply that the (alanine) uniport was responsible for AIB influx and efflux under hypo-osmotic conditions, and the difference in specificity for AIB supports the suggestion that the uniport is distinct from the (alanine) antiport.

It was also found that the giardial alanine uniport was $\mathrm{Na}^{+}$-independent and was activated solely by the decreased osmolality, since replacing $\mathrm{NaCl}$ in PBS to choline chloride, $\mathrm{KCl}$ or mannitol, and the presence of ionophores, had no effect on giardial VA alanine efflux. A $\mathrm{Na}^{+}$-independent amino acid uniporter has previously been observed in fish erythrocytes and Ehrlich ascites tumour cells, where taurine is the major osmolyte (Fincham et al., 1987; Hoffmann \& Lambert, 1983; Huxtable, 1992; Haynes \& Goldstein, 1993). It was recently reported that $\mathrm{Na}^{+}$-independent taurine transport from skate erythrocytes might be via a VA anion channel (Goldstein \& Brill, 1991; Haynes \& Goldstein, 1993; Kirk et al., 1992). This hypothesis was based largely on the observation that chloride channel blockers also inhibited the VA taurine transport. However, the chloride channel blockers furosemide and niflumate had no effect on giardial VA alanine efflux, implying that an anion channel accommodating a wide range of solutes is unlikely to account for alanine efflux in Giardia under hypotonic conditions. Among the inhibitors tested, only PHMB exhibited significant inhibition of VA alanine efflux and also blocked the giardial RVD after the swelling process (Fig. 1). Even considering that this inhibitor is relatively nonspecific, these findings can best be explained by the unidirectional alanine efflux playing a major role in giardial RVD.

There are several lines of evidence that the release of alanine and other amino acids was not due to rupturing of the cells. Firstly, the almost total loss of intracellular alanine within $3 \mathrm{~min}$ under hypo-osmotic pressure of $157 \mathrm{mOsm} \mathrm{kg} \mathrm{g}^{-1}$ would require the osmolysis of all or nearly all cells. However, the Giardia trophozoites remained intact and motile. Secondly, all intracellular amino acids would be expected to be released under hypoosmotic conditions, if the release was due to the osmolysis. However, specificity was observed, with the intracellular pools of glutamate and ornithine remaining unchanged (Figs 1 and 2). Thirdly, the ability of Giardia to operate RVD after the cell swelling process also argues against cell rupture. Finally, the temperature dependence and relatively high $Q_{10}$ of alanine efflux under hypotonic conditions (Fig. 5) would be inexplicable by cell rupture.

In summary, the observations reported here indicate that alanine is a major osmolyte in Giardia, and that the giardial response to hypotonic conditions involves transmembrane movement of alanine via an alanine uniport system. This may be of significance in understanding the development of osmoregulatory mechanisms in eukaryotic organisms (Lenaers et al., 1988; Sogin et al., 1989).

\section{ACKNOWLEDGEMENTS}

Jeong $\mathrm{H}$. Park was in receipt of an Overseas Postgraduate Research Scholarship. This work was supported, in part, by grants from the National Health and Medical Research Council of Australia.

\section{REFERENCES}

Briones, M. R. S., Nelson, K., Beverley, S. M., Affonso, H. T., Camargo, E. P. \& Floeter-Winter, L. M. (1992). Leishmania tarentolae taxonomic relatedness from phylogenic analysis of the small subunit ribosomal RNA gene. Mol Biochem Parasitol 53, 121-128.

Chamberlin, M. E. \& Strange, K. (1989). Anisosmotic cell volume regulation: a comparative view. Am J Pbysiol 257, C159-C173.

Darling, T. N., Burrows, C. M. \& Blum, J. J. (1990). Rapid shape change and release of ninhydrin-positive substances by Leishmania major promastigotes in response to hypo-osmotic stress. $J$ Protozool 37, 493-499.

Edwards, M. R., Gilroy, F. V., Jimenez, B. M. \& O'Sullivan, W. J. (1989). Alanine is a major end product of metabolism of Giardia lamblia: proton nuclear magnetic resonance study. Mol Biochem Parasitol 37, 19-26. 
Edwards, M. R., Knodler, L. A., Wilson, J. R. \& Schofield, P. J. (1993). The transport and metabolism of alanine by Giardia intestinalis. Mol Biochem Parasitol 61, 49-58.

Fincham, D. A., Wolowyk, M. W. \& Young, J. D. (1987). Volumesensitive taurine transport in fish erythrocytes. J Membrane Biol 96, 45-56.

Gilles, R. (1987). Volume regulation in cells of euryhaline invertebrate. In Cell Volume Control: Fundamental and Comparative Aspects in Animal Cells, pp. 205-247. Edited by R. Gilles, A. Kleinzeller \& L. Bolis. New York: Academic Press.

Goldstein, L. \& Brill, S. R. (1991). Volume-activated taurine efflux from skate erythrocytes: possible band 3 involvement. Am J Pbysiol 260, R1014-R1020.

Haynes, J. K. \& Goldstein, L. (1993). Volume-regulatory amino acid transport in erythrocytes of the little skate, Raja erinacea. $A m \mathrm{~J}$ Physiol 265, R173-R179.

Hoffmann, E. K. \& Lambert, I. H. (1983). Amino acid transport and cell volume regulation in Ehrlich ascites tumour cells. J Physiol 338, 613-625.

Huxtable, R. J. (1992). Physiological actions of taurine. Pbysiol Rev 72, 101-163.

Kirk, K., Ellory, J. C. \& Young, J. D. (1992). Transport of organic substrates via a volume-activated channel. J Biol Cbem 267, 23475-23478.

Knodler, L. A., Edwards, M. R. \& Schofield, P. J. (1994). The intracellular amino acid pools of Giardia intestinalis, Trichomonas vaginalis and Critbidia luciliae. Exp Parasitol 79, 117-125.
Lenaers, G., Nielsen, H., Engberg, J. \& Herzog, M. (1988). The secondary structure of large-subunit rRNA divergent domains, a marker for protist evolution. Biosystems 21, 215-222.

Lepley, P. R. \& Mukkada, A. J. (1983). Characteristics of an uptake system for $\alpha$-aminoisobutyric acid in Leishmania tropica promastigotes. $J$ Protozool 30, 41-46.

Moyes, C. D., Moon, T. W. \& Ballantyne, J. S. (1986). Osmotic effects on amino acid oxidation in skate liver mitochondria. $J$ Exp Biol 125, 181-195.

Nygaard, T., Bennett, C. C., Grossman, G., Edwards, M. R. \& Schofield, P. J. (1994). Efflux of alanine by Giardia intestinalis. Mol Biocbem Parasitol 64, 145-152.

Padan, E., Zilberstein, D. \& Rottenberg, H. (1976). The proton electrochemical gradient in Escherichia coli cells. Eur J Biochem 63, 533-541.

Schofield, P. J., Edwards, M. R., Matthews, J. \& Wilson, J. R. (1992). The pathway of arginine catabolism in Giardia intestinalis. Mol Biochem Parasitol 51, 29-36.

Shotwell, M. A. \& Oxender, D. L. (1983). The regulation of neutral amino acid transport by amino acid availability in animal cells. Trends Biochem Sci 8, 314-316.

Sogin, M. L, Gunderson, J. H., Elwood, H. J., Alonso, R. A. \& Peattie, D. A. (1989). Phylogenic meaning of the kingdom concept: an unusual ribosomal RNA from Giardia lamblia. Science 243, 75-77.

Received 9 January 1995; revised 20 April 1995; accepted 13 June 1995. 